\title{
. \\ OS SONS COMO \\ LINGUAGENS ESPACIAIS
}

- ALESSANDRO DOZENA*

Resuma: Nossa experiência espacial envolve a escuta de fantes sonoras musicais e não musicais (naturais ou artificiais), sendo essa experiência subjetivamente apropriada a partir da ordenamento dos sans e das ruídas no âmbita de nassas padrões de racionalidade. Qs ruídas, sans e músicas têm cada vez mais feito parte das estudas geográficas, senda que a escuta ativa torna-se valiosa nesse processa, da mesma forma que a visão. — objetivo do presente artigo é evidenciar o fato de que as sons se constituem linguagens espaciais, um meio de comunicar ideias ou sentimentas a partir de fontes sonoras. Essa propasiçãa infere que a ouvir músicas um indivíduo também "ouve o território", na medida em que características musicais como melodia, harmonia, escala e ritmo, relacionam-se a condicionamentos espaciais específicus.

Palavras-Chave: sons; músicas; gengrafia; linguagem; espacial.

\section{Ecos na Geografia}

Definir o olhar com a linguagem do som, é mais fácil de afinar

Olhar com escuta, é deixar a sonoridade saltitar,

Geografando com solfejar

Conhecendo-se o som, muda-se o tom

Para maior ou menor, na métrica certa, A música desperta, redefine o que é o olhar.
Há décadas a Geografia brasileira vem considerando os trabalhos realizados sobre as dimensões musicais e sonoras, em especial os escritos em francês e inglês, que foram publicados principalmente após a "virada cultural" na década de 1980, aparecendo com destaque no debate acadêmico internacional. No Brasil, essa discussão intensificou-se nos últimos anos, 
alicerçada em questões que envolvem territórios musicais ${ }^{1}$, percepções e representações espaciais dos sons e das músicas, paisagens sonoras, cenas musicais, identidades territoriais musicais, a dimensão espacial dos sons e das músicas; além do uso das letras de músicas como ferramenta didática no ensino de geografia. Igualmente, a abordagem dos imaginários geográficos promovidos pelos sons e pelas músicas ganha destaque na atualidade (Lindón; Hiernaux, 2012), propondo territorialidades conformadas pela fluidez sonora e pelos processos musicais.

Dando continuidade aos trabalhos precursores, a exemplo dos realizados pelo francês Georges de Gironcourt (1932), os (as) geógrafos (as) brasileiros (as) têm posto suas pesquisas em movimento, inserindo os sons e as músicas no cerne das suas abordagens geográficas e ampliando os diálogos com outras disciplinas e perspectivas de compreensão da realidade, a exemplo da Antropologia, Psicologia, Filosofia, Musicologia, História, Etnomusicologia, Sociologia e Pedagogia (Canova; Raibaud, 2017).

Buscamos com o presente artigo evidenciar o fato de que os sons constituem linguagens espaciais, um meio capaz de comunicar ideias ou sentimentos a partir de fontes sonoras. Essa proposição considera que ao ouvir música um indivíduo também "ouve o território", na medida em que características musicais como melodia, harmonia, escalas e ritmos relacionam-se a condicionamentos espaciais específicos (por exemplo, o frevo recifense guarda uma relação intrínseca com os locais de sua produção), ou ainda quando o contato com a paisagem é inspirado por uma canção ou ritmo musical, e incita imaginários geográficos (a exemplo da bossa nova ou do funk, e a relação imediata que estabelecemos com a cidade do Rio de Janeiro). Conforme sugere Raul Borges, as musicalidades estão associadas a sociedades espacializadas em momentos específicos:

\begin{abstract}
A música pode ser percebida como uma linguagem viva de um contexto histórico-geográfico, assim como nas articulações escalares particulares de cada lugar há implícita uma certa musicalidade (BORGES, 2008, p. 289).
\end{abstract}

Nossa experiência espacial também abarca a escuta de fontes sonoras não musicais (naturais ou artificiais), sendo essa experiência subjetivamente apropriada a partir do ordenamento dos sons e dos ruídos no cerne de nossos padrões racionais de pensamento.

Essa experiência auditiva do espaço abrange a escuta das emissões sonoras e a possibilidade de localizá-las e organizá-las 
em termos de timbres e outros aspectos sonoros, a exemplo da percepção de vazio ou preenchimento ao chacoalharmos um recipiente de madeira com moedas dentro, ou uma lata com feijões transformada em um ganzá. Evidentemente, a acuidade da audição não se equivale à da visão, mas é igualmente necessária para a percepção espacial:

No âmbito sensorial e fisiológico, apesar do campo visual aberto, a visão é focada em um ponto de maior acuidade designado fóvea. Mas a audição apreende o espaço sem um centro ou sem um foco tão nítido. A audição permite a capacidade de localização, mas de modo diferente da visão central, não existe uma "audição central". Isto deve-se a um fator fisiológico em parte explicado pela topografia do sistema visual prolongando a informação do espaço observado nos tecidos corticais, em oposição à ausência de topografia da 'membrana basilar' onde se localizam os sensores de som no interior do ouvido. Nesse sentido, e tal como acontece com a visão, é importante ter dois ouvidos para estabelecer posições no espaço. A diferença de tempo na recepção de um som permite localizar a sua origem e criar uma representação tridimensional das fontes sonoras (MATLIN; FOLEY, 1996, p. 298 citados por ALMEIDA, 2018, p. 166).
Por isso, o poema que abre o artigo sugere que ao definirmos o olhar com a linguagem do som, redefinimos o próprio ato de olhar. Tal premissa dialoga como a definição de linguagem encontrada no mais importante dicionário da língua portuguesa, o Dicionário Houaiss, ao asseverar que se trata de "qualquer meio sistemático de comunicar ideias ou sentimentos através de signos convencionais, sonoros, gráficos e gestuais".

Vale lembrar que música é a combinação harmoniosa e expressiva de sons, um conjunto de sons vocais, instrumentais ou mecânicos com ritmo, harmonia e melodia. A música é uma manifestação artística que se revela por meio de sons, seguindo regras variáveis conforme a época, a civilização, os modos de vida e o ambiente natural. Daí a importância de estarmos sempre nos referindo a sons e músicas, com a intenção de abarcar a plenitude de possibilidades sonoras (desde os muzaks ${ }^{2}$ ouvidos nas lojas comerciais, até as músicas de caráter religioso que são reverberadas em espaços distintos).

Em outros termos, as músicas podem ser definidas como sons humanamente organizados, relacionados a padrões de organização humana e de sons 
produzidos como resultados de interações sociais (Blacking, 1973).

Assim sendo, a materialidade espacial também desempenha um importante papel nas experiências musicais: seja na arquitetura do teatro, permitindo uma maior projeção sonora, na posição dos músicos em uma orquestra/banda musical em relação ao público, ou com relação aos efeitos acústicos advindos da reverberação natural a partir da reflexão sonora.

\section{Sons, condicionamentos espaciais e a escuta ativa}

Desde o início do século XXI muitas composições musicais tratam a dimensão espacial como um elemento proeminente. Esse é o caso da música eletrônica, em que o espaço tem sido explorado não apenas em relação à posição dos músicos, do público e ao uso da reverberação, mas também no que diz respeito aos efeitos provocados pelo movimento do som acompanhado de uma evidente dispersão sonora.

O corpo também traz as marcas da cultura no contexto espacial em que está inserido, apontando caminhos para a compreensão de uma performatividade que parte do próprio corpo e envolve os movimentos realizados e influenciados pelas musicalidades presentes nos lugares. Deste modo, dá-se um diálogo com o lugar, que se apresenta no corpo, a partir de elementos do contex to espacial. Não é à toa que dos diferentes modos de apropriação criam-se subjetivações territoriais que se reproduzem nas músicas, nas melodias, nos ritmos, nas danças, nas letras e nas harmonias.

Há uma relação entre o corpo e o contexto espacial em que este se insere, e cada sociedade se expressa distintamente segundo os corpos e suas construções culturais diferenciadas. Inserida em seu contexto espacial particular, cada sociedade produz sua cultura e dela é o resultado.

Dialogando com o pensamento de Merleau-Ponty (1964) podemos considerar que o corpo constrói processos de identificação entre o mundo pessoal e o mundo público e, na interação com o outro, reafirmam-se ou mesmo se descobrem alguns aspectos da própria identidade. Pelo ato de dançar ou tocar, o corpo articula uma linguagem que coloca os sujeitos em grupos territorialmente localizáveis, grupos que guardam relações ancestrais em que a experiência corporal fixa $o$ território na existência, na medida em que o corpo é o ser no território.

Podemos ampliar essa reflexão se consideramos que a questão da 
corporeidade está diretamente associada a questão da musicalidade, que por sua vez, relaciona-se com a riqueza de sons provenientes dos cantos, dos rituais religiosos e da dança. Desse modo, a musicalidade pode ser vista como um álibi para se atingir alguns fatos geográficos, sobretudo ao constatarmos que as letras e as sonoridades trazem consigo uma historicidade que usa metáforas importantes para a desconstrução ou construção de conceitos e pré-conceitos socialmente estabelecidos.

Outro fato interessante é a percepção, nas pesquisas geográficas, de que os sons e as músicas atuam como motivadores existenciais e estão intrinsecamente conectados aos processos de territorializações, enraizamentos identitários e migrações populacionais. Tais processos são acompanhados por ambiguidades na constituição das identidades espaciais e musicais (Crozat, 2016).

Um dos principais efeitos da globalização foi a divulgação dos sons e estilos musicais de diferentes localidades, contribuindo com a configuração de territórios musicais híbridos. Há inclusive uma significativa tendência pelo revivalismo, com a predisposição e a intenção de reviver estilos musicais e músicas do passado, atualizando-as em um contexto cultural demarcado por características pós-modernas (Bell; Johansson, 2009).

O fenômeno mundial das "músicas de massa" dialoga com o nosso tempo, interagindo com narrativas locais e globais, integrando gostos musicais desterritorializados e ao mesmo tempo territorializados por intermédio das identificações locacionais, que se conectam com as lógicas comunitárias e o apego individual e coletivo aos lugares. Assim sendo, os territórios musicais não se caracterizam como conservatórios musicais, mas revelam recriações constantes e uma das faces mais evidentes da globalização: o contato cultural.

Nesse contexto, os sons e as músicas geram espacialidades, situadas entre a mobilidade e a fixidez, entre a fluidez e a ancoragem territorial. Nele, a utopia é criada pelas sensações sonoras promovidas em festas raves, festivais, apresentações musicais ou batucadas (Dozena, 2017). Muitas interpretações geográficas dos fatos musicais procuram compreender a recomposição dos territórios musicais diante das narrativas atuais, e atualizar os discursos históricos presentes nas letras de músicas, replicando-os especialmente nas novas redes sociais e suas mídias digitais (De Nora, 2005). Vale destacar que ao redor dos 
sons e das músicas se estruturam cosmovisões que agem como operatrizes das ações sociais.

Esse debate tem como consequência direta a amplificação dos horizontes teóricos e metodológicos sobre as dimensões geográficas dos fenômenos sonoros e musicais. Embora a Geografia ainda seja uma ciência primordialmente visual, a escuta ativa passou a ter, no século XXI, um papel essencial nas pesquisas geográficas (Canova; Raibaud, 2017). Nesse sentido, muitos pesquisas têm buscado a importância dessa escuta ativa na interpretação geográfica dos territórios musicais em sua significação e sentido social, tangenciando temas relacionados a globalização e territórios musicais, ruídos e sons das e nas cidades, músicas e espaços públicos, eventos musicais urbanos $\mathrm{e}$ fenômenos sonoros, percepções musicais individuais e coletivas, paisagens sonoras, oralidades e discursos musicais.

Nossa experiência espacial também passa pela escuta de fontes sonoras não musicais (naturais ou artificiais), sendo essa experiência subjetivamente apropriada, a partir do ordenamento dos sons e dos ruídos no âmbito de nossos padrões de racionalidade. Os ruídos, sons e músicas podem se conectar nos estudos geográficos, sendo que a escuta ativa torna-se valiosa nesse processo, complementarmente a visão.

Essa musicalidade pode ser trazida ancestralmente pelas coletividades, atendendo não somente às vontades de reprodução material e às necessidades de sobrevivência, mas também expressando muitas especificidades culturais que efetivamente mobilizam e animam os agrupamentos sociais; ao mesmo tempo em que revelam histórias não - oficiais que passam a ser contadas pelas ruas e áreas diversas das cidades brasileiras.

Igualmente, as músicas contribuem para a criação e fortalecimento de laços emotivos e humanos com os lugares, além de demarcarem corporeidades, territorialidades e relações sócio- espaciais; sendo produzidas a partir de estímulos colocados pelos lugares e por isso mesmo evidenciando o sentido desses lugares.

Algumas características de lugares específicos oferecem pré-condições às novas ideias musicais. Até mesmo alguns instrumentos musicais são criados conforme as condições propiciadas pelos lugares, condições retomadas e reverberadas a partir do repertório cultural próprio de cada agrupamento social. Em outras palavras, há uma condição espacial que influencia a criação musical nos diferentes lugares do mundo. 


\section{Considerações finais: Identidades musicais, identidades dos lugares e novos horizontes geográfico-sonoros}

A noção de territorialidade considera a apropriação e o controle exercido no território pelos humanos, a partir de mediações espaciais de poder que podem ser simbólicas e/ou concretas. Essa noção muito se desenvolveu pelo contato com os antropólogos, intercambiando questões referidas a simbolismos, heranças e gêneros de vida. As territorialidades são, assim, as ações estratégicas de demarcação, de prática de poder, controle e vivência territorial exercidas pelos humanos, em um contex to de criação de regras para o acesso, os usos, os comportamentos e a circulação territorial.

As territorialidades forjadas por aspectos sonoros podem fomentar identidades com base territorial, trazendo conexões com padrões passados e presentes de povoamento, migração, etnicidades, heranças musicais, estilos de vida e condições socioeconômicas. Torna-se relevante atentar para o fato de que além de um corpo fisiológico existe um corpo social, criador de uma musicalidade que se ratifica na existência individual e coletiva.

Há muitas evidências de que algumas habilidades sensório-motoras dos sujeitos são ativadas nesta construção de identidades de base territorial. Um exemplo claro, no âmbito musical, é a própria estrutura rítmica e melódica que emerge como uma construção do processo de representação social, uma representação estabelecida cultural, ideológica e tecnicamente. Como já assinalamos, existem características de lugares específicos que oferecem pré-condições às novas ideias musicais.

Não só a música, mas tudo o que é artístico é transversal à vida humana em suas múltiplas dimensões, exerce fascínio e influência sobre os humanos. São dimensões que envolvem criações e que fascinam os humanos: música, literatura, dança, teatro, criações sonoras, desenho animado, arquitetura, escultura, pintura, cinema, design, gastronomia, fotografia, vídeos, cartografia entre outras manifestações. Tudo isso encanta os humanos por apresentar possibilidades de diálogos possíveis entre práticas que enredam as nossas experiências cotidianas com experiências vividas espaçoartisticamente; e por demonstrar o melhor que o ser humano pode produzir.

Como deixamos claro nas linhas precedentes, a música amplia a possibilidade de harmonização com nós mesmos e com as pessoas ao nosso redor. Ela aciona os nossos imaginários, nossas percepções, sensações, nos motiva, 
promove a valorização das identidades locais e amplia as sensações de pertencimento.

Além da racionalidade hegemônica existem outras racionalidades, configuradas em territórios musicais simbólicos e materiais. Torna-se cada vez mais indispensável a reflexão sobre os mecanismos e táticas cotidianas valorizadoras das experiências sonoras existentes no interior desses territórios.

Presenciamos na atualidade um movimento etnogeográfico que vem se adensando nos últimos anos, voltando-se para a descrição e explicação dos significados espaciais das experiências sonoras e musicais. Tal movimento, evidencia que os territórios musicais são capazes de estreitar as interações sociais, fortalecer os vínculos comunitários e as práticas de sociabilidade, revigorando os sentimentos de pertencimento a eles.

A partir da leitura do artigo, constata-se que vale o esforço de interpretar os discursos e códigos espaciais de nosso tempo, a partir de reflexões geográficas empregadas em perspectivas múltiplas. $\mathrm{O}$ artigo evidenciou a necessidade da diversidade temática, metodológica e conceitual como um fundamento ao diálogo necessário para a compreensão da complexidade do mundo contemporâneo e dos novos processos que a acompanham. Considerando tudo isso, a paisagem passa a ser aquilo que o olhar abarca, a mente concebe e os ouvidos captam. E a geografia se abre para um universo de temas de pesquisas a se explorar.

Ao considerar que geografia e música são campos científicos e/ou artísticos complementares, julgamos que ambos expressam a possibilidade de se constituírem em experimentações que transcendem os limites das disciplinas acadêmicas formalmente estabelecidas; tornando-se campos que podem dialogar entre si, de modo plural e motivador.

Assim sendo, ao perceber que as fronteiras disciplinares podem ser momentaneamente rompidas com articulações não hierárquicas, as temáticas comuns entre os dois campos emergem vigorosas e desprovidas de intolerâncias e argumentos acerca da falta de rigor científico; argumentos que, aliás, contribuem para a consolidação das disciplinas científicas como instituições de poder.

Acreditamos que o olhar geográfico sobre o fato sonoro e musical deve estar diretamente relacionado a preocupação em acionar os princípios clássicos da Geografia, a exemplo dos princípios da causalidade, da localização, da extensão, da diferenciação de áreas, da conexão, da 
unidade e da atividade. Ao acioná-los, a dimensão espacial dos fatos sonoros e musicais tornar-se-á evidente.

O inesgotável manancial musical brasileiro solicita não só aos pesquisadores (as) mas também aos professores (as) a sua constante compreensão geográficomusical. Em outras palavras, as sonoridades "vivas" presentes nos territórios musicais brasileiros solicitam a sua "leitura musical" e a compreensão das heranças musicais presentes no universo melódico e rítmico nacional. Exemplarmente, o samba, o afoxé, o rock, o funk e o maracatu atuam como alicerces da música popular brasileira, acrescentado da plêiade de ritmos, sonoridades e estilos encontrados no Brasil, e dos que chegam a nossos alunos pela internet e nos convidam a uma abertura para novos procedimentos didático-pedagógicos.

Os professores (as) precisam ir além do uso da letra de músicas em suas aulas como ferramenta didática no ensino de geografia, embora saibamos que esse uso continua tendo a sua validade e relevância. Como professores (as) somos convidados a ouvir as músicas com um caráter lúdico e vívido, colocando em movimento o exercício da desconstrução dos campos científicos mais afeitos às regras e padrões normativos que aprisionam as suas sonoridades.
Há hoje o convite para uma aproximação criativa das manifestações artísticas pelos professores (as), evidenciando-se as potencialidades dessas aproximações. No caso da música, explorando os ritmos e os instrumentos musicais, por exemplo, e associando-os ao seu contexto de surgimento e reprodução. $\mathrm{Ou}$ ainda, construindo instrumentos musicais com sucatas, realizando jogos de improvisação a partir dos elementos culturais locais (emboladas, rap, repente, catira, tambores, danças de roda, uso de mamulengos, literatura de cordel, entre outros).

E para construir essa nova forma de ouvir o mundo, precisamos igualmente usar as cantigas folclóricas regionais, os ritmos e as danças locais), a fim de avançarmos em outras propostas relacionadas ao processo de ensino e aprendizagem. Em uma experiência anterior com a Orquestra Orgânica Performática (em São Paulo capital), experimentamos a potencialidade da percussão corporal e da produção de sons múltiplos (como a tentativa de reprodução dos sons da natureza) envolvendo o corpo e instrumentos musicais construídos com materiais recicláveis. Esse é um tipo de prática que pode motivar os professores a experimentar novos procedimentos didáticos, interessando-se por mais de uma 
área do conhecimento, e explorando a sua criatividade científica e artística.

Obviamente é muito importante que esse tipo de conhecimento seja posto na formação universitária dos professores (as), para que por exemplo, mesmo sem ter tido qualquer tipo de formação musical, os professores (as) possam ter o conhecimento básico dos tipos de instrumentos musicais, dos jogos de improvisação e outras estratégias didáticas amplificadoras da aprendizagem por meio das músicas e dos sons.

Alguns professores (as) têm inserido músicas em suas aulas e vêm ampliando as discussões com outras disciplinas e perspectivas de compreensão da realidade, a exemplo das interações que acontecem entre Geografia, Filosofia, História, Português, Matemática e Educação Artística. Isso é muito salutar, na medida em que amplia os horizontes do pensar. Materiais interativos, como o que é utilizado no ensino a distância do curso de graduação em Geografia da UFRN $^{3}$, evidenciam a tentativa de exploração de recursos artísticos como músicas, documentários e fotografias; pelo diálogo com os outros campos do saber.

Nos ateliês realizados com pedagogas e professoras (es) de Geografia no estado do Rio Grande do Norte, recebo muitos depoimentos sobre o que estas (es) já realizam nas escolas em que trabalham. Noto um estranhamento inicial com relação a essa abordagem geográfica dos sons e músicas, com posterior encantamento, pois elas percebem que os conteúdos de caráter geográfico e histórico potencializam a expansão dessas capacidades de realização de mapeamentos, inventários de paisagens imaginadas, mapas mentais, percussão corporal como algo que contribui com a ritmicidade das crianças e jovens, além de músicas e cantigas resgatadas da cultura local e que tocam profundamente os estudantes.

Há hoje uma melhor articulação e expansão das reflexões teóricas que envolvem as relações entre ensino de geografia e música. No ambiente acadêmico alguns autores (as) se inserem em um debate vigoroso, tanto no plano nacional quanto internacional, o que tem reverberado na produção de livros e artigos, além de ter influenciado a inserção de temáticas culturais nos encaminhamentos presentes em livros didáticos e paradidáticos. Esse interesse renovado pela pesquisa sobre as interfaces entre geografia, sons e música no Brasil reflete de certo modo a criatividade dos pesquisadores, professores e o próprio potencial advindo da música brasileira.

Vale lembrar que esse percurso temático não se iniciou agora, mas vem 
sendo construído nos últimos anos por dezenas de contribuições, e que tendem a ganhar mais propulsão. Fica o convite para adentrarmos nesses novos horizontes geográfico-sonoros que se anunciam.

\section{NOTAS}

* Tornou-se geógrafo pela Universidade Estadual Paulista (UNESP-Rio Claro) e músico pela Universidade Livre de Música (ULM-São Paulo). É Professor Associado do Departamento e do Programa de Pós-Graduação em Geografia da Universidade Federal do Rio Grande do Norte (PPGE-UFRN), onde dirige o grupo de pesquisa Festas, Identidades e Territorialidades (FITCNPq), e professor do Mestrado Profissional em Geografia (GEOPROF-UFRN). Realizou mestrado e doutorado em Geografia Humana na Universidade de São Paulo (USP-São Paulo), com doutorado-sanduíche na Universidad de Barcelona (UB). Realizou estágio pós-doutoral na Université Paul-Valéry Montpellier (UPV) como bolsista da CAPES, e foi convidado para atuar como Professor Visitante na mesma universidade em 2020. Organizou e publicou os livros: Geografia e Música: Diálogos (2016), Espaço-Tempo: Enredos entre Geografia e História (2015), A Geografia do Samba na Cidade de São Paulo (2012) e São Carlos e seu Desenvolvimento: Contradições Urbanas de um Polo Tecnológico (2008). É Tutor do Programa de Educação Tutorial - PET Geografia (UFRN), integrante do Grupo Vocal Octo Voci da Escola de Música da UFRN (EMUFRN), e membro do Comitê Géographies Culturelles vinculado ao Comitê Nacional Francês de Geografia (CNFG).

1 Para uma abordagem teórica sobre territórios musicais, ver: L'Information géographique Géomusique. Armand Colin, vol.4, 2018, 152p.
${ }^{2}$ Segundo o Cambridge Dictionary, "um nome de marca para música gravada que é tocada continuamente em locais públicos, como aeroportos, hotéis e lojas, para que as pessoas se sintam relaxadas" (a brand name for recorded music that is played quietly and continuously in public places, such as airports, hotels, and shops, to make people feel relaxed). Tradução nossa. Disponível em: https://dictionary.cambridge.org/pt/dicionario/in gles/muzak

3 Material disponível em: bibliotecadigital.sedis.ufrn.br , interativos , geografia-cultural > base

\section{REFERÊNCIAS BIBLIOGRÁFICAS}

ALMEIDA, Paulo Freire de. Paisagem e Visualidade na Música: Lugares e Universos Paralelos. In: AZEVEDO, FURLANETTO e DUARTE (org.). Geografias Culturais da Música. Braga, 2018.

BELL, Thomas L; JOHANSSON, Ola. Sound, society and the geography of popular music. Ashgate; Har/Dig edition, 2009

BLAKING, John ¿Hay Musica en el Hombre? Alianza Editorial, 1973, p. 63.

BORGES, Raul. Escala geográfica e partitura musical: considerações acerca do sistema modal e tonal. In: Zeny Rosendahl; Roberto Lobato Corrêa. (Org.). Espaço e cultura: pluralidade temática. 1a. ed. Rio de Janeiro: EDUERJ, 2008, v. 1, p. 279-296.

CANOVA, Nicolas; RAIBAUD, Yves. Les figures d'attachement dans la géomusique. L'Information géographique. Vol. 81, 2017/1, p. 8-19.

CROZAT, Dominique. Jeux et Ambigüités de la Construction Musicale des Identités Spatiales. In: DOZENA, Alessandro. (Org.). Geografia e Música: Diálogos. Natal: Edufrn, 2016, p. 49-83.

DE NORA, Tia. Music and Social Experience. In: Jacobs, M. D. and Weiss Hanrahan. The Blackwell companion to the sociology of culture, Oxford, Blackwell Publishing, 2005, p. 147-162.

DOZENA, Alessandro. L'imaginaire utopique brésilien dans les pratiques festives européennes. Confins 
- Revue franco-brésilienne de géographie, Número 33, 2017.

GIRONCOURT, Georges de. Une science nouvelle : la géographie musicale. Université de Nancy, 1932.

LINDÓN, Alícia; HIERNAUX, Daniel. Geografías de lo imaginario. Barcelona: Anthropos Editorial, 2012, $251 \mathrm{p}$.

MATLIN, Margaret W; FOLEY, Hugh. J. Sensacion y Percepcion. Naucalpan de Juárez: Prentice Hall Hispano Americana, 1996.
MERLEAU-PONTY Maurice. Le Visible et l'Invisible suivi de notes de travail. Paris, Gallimard, 1964.

SCHAFER, Raymond M. A afinação do mundo. São Paulo: EdUNESP, 1977.

\section{SONS COMME LANGAGE SPATIAL}

RESUMÉ: NOTRE EXPÉRIENCE SPATIALE CONSISTE À ÉCOUTER DES SOURCES SONORES MUSICALES ET NON MUSICALES

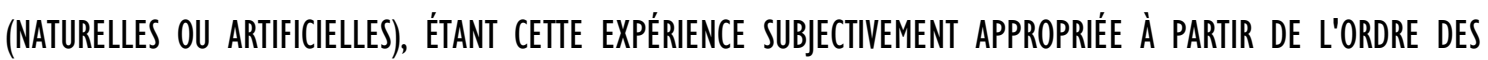
SONS ET DES BRUITS DANS LE CADRE DE NOS STANDARDS DE RATIONALITÉ. LES BRUITS, LES SONS Et LA MUSIQUE FONT

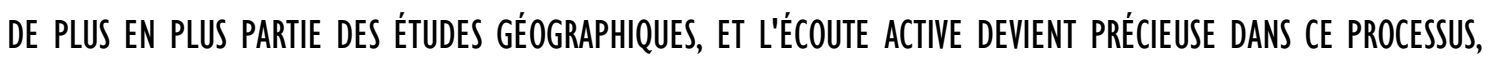
AINSI QUE LA VISION. LE BUT DE CET ARTICLE EST DE METTRE EN ÉVIDENCE LE faIt QUE LES SONS SONT DES LANGAGES SPATIAUX, UN MOYEN dE COMMUNIQUER deS IDÉES OU DES SENTIMENTS À PARTIR dE SOURCES SONORES. CETtE proposition laISSE entendRe QU'En ÉCOUTANt de LA MUSIQUE, UN INDIVIDU "ENTEND ÉGalement le terRitOIRE", DANS la MESURE OÙ Les CARACTÉRISTIQUES MUSICALES TELLES QUE LA MÉLODIE, L'HARMONIE, L'ÉCHELLE Et LE RYTHME, SONT LLÉES À DES CONDITIONS SPATIALES SPÉCIFIQUES.

MOTS-CLÉS: SONS; MUSIQUE; GÉOGRAPHIE; LANGAGE; SPATIAL

\section{SOUNDS AS SPATIAL LANGUAGE}

ABSTRACT: OUR SPATIAL EXPERIENCE INVOLVES LISTENING TO MUSICAL AND NON-MUSICAL SOUND SOURCES (NATURAL OR ARTIFICIAL), THIS EXPERIENCE BEING SUBJECTIVELY APPROPRIATE FROM THE ORDERING OF SOUNDS AND NOISES WITHIN THE SCOPE OF OUR STANDARDS OF RATIONALITY. NOISES, SOUNDS AND MUSIC HAVE INCREASINGLY BEEN PART OF GEOGRAPHIC STUDIES, AND ACTIVE LISTENING BECOMES VALUABLE IN THIS PROCESS, AS WELL AS VIISION. THE PURPOSE OF THIS ARTICLE IS TO HIGHLIGHT THE FACT tHAT SOUNDS ARE SPATIAL LANGUAGES, A MEANS OF COMMUNICATING IDEAS OR FEELINGS FROM SOUND SOURCES. THIS PROPOSITION INFERS THAT WHEN LISTENING TO MUSIC AN INDIVIDUAL aLSO "HEARS the terRITORY", INSOFAR AS the MUSICAL CHARACTeRISTICS SUCH AS MELODY, HARMONY, SCALE AND RHYTHM, ARE RELATED TO SPECIFIC SPATIAL CONDITIONS.

KEYWORDS: SOUNDS; MUSIC; GEOGRAPHY; LANGUAGE; SPATIAL. 